\title{
The descriptive epidemiology of primary lung cancer in an Alberta cohort with a multivariate analysis of survival to two years
}

\author{
Sandor J Demeter MHSc MD FRCPC ${ }^{1}$, Chester Chmielowiec MSc MD FRCPC ${ }^{2}$, Wayne Logus MSc ${ }^{2}$, \\ Pauline Benkovska-Angelova MD², Philip Jacobs $\mathrm{PhD}^{3}$, David Hailey $\mathrm{PhD}^{3}$, Alexander McEwan MB FRCPC
}

\begin{abstract}
SJ Demeter, C Chmielowiec, W Logus, et al. The descriptive epidemiology of primary lung cancer in an Alberta cohort with a multivariate analysis of survival to two years. Can Respir J 2003;10(8):435-441.
\end{abstract}

BACKGROUND: Lung cancer contributes significantly to cancer morbidity and mortality. Although case fatality rates have not changed significantly over the past few decades, there have been advances in the diagnosis, staging and management of lung cancer. OBJECTIVE: To describe the epidemiology of primary lung cancer in an Alberta cohort with an analysis of factors contributing to survival to two years.

PATIENTS AND METHODS: Six hundred eleven Albertans diagnosed with primary lung cancer in 1998 were identified through the Alberta Cancer Registry. Through a chart review, demographic and clinical data were collected for a period of up to two years from the date of diagnosis.

RESULTS: The mean age at diagnosis was 66.5 years. The majority of cases (92\%) were smokers. Adenocarcinoma, followed by squamous cell carcinoma, were the most frequent nonsmall cell lung cancer histologies. Adenocarcinoma was more frequent in women, and squamous cell carcinoma was more frequent in men. The overall twoyear survival rates for nonsmall cell, small cell and other lung cancers were $24 \%, 10 \%$ and $13 \%$, respectively. In multivariate analysis, stage, thoracic surgery and chemotherapy were significantly associated with survival to two years in nonsmall cell carcinoma; only stage and chemotherapy were significant in small cell carcinoma.

CONCLUSIONS: This study provides a Canadian epidemiological perspective, which generally concurs with the North American literature. Continued monitoring of the epidemiology of lung cancer is essential to evaluate the impact of advances in the diagnosis, staging and management of lung cancer. Further clinical and economic analysis, based on data collected on this cohort, is planned.

Key Words: Canada; Epidemiology; Lung neoplasm; Prognosis

\section{L'épidémiologie descriptive de cancer} pulmonaire primaire dans une cohorte de l'Alberta, avec une analyse multivariée de la survie après deux ans

\begin{abstract}
HISTORIQUE : Le cancer du poumon contribue énormément à la morbidité et à la mortalité du cancer. Bien que les taux de mortalité n'aient pas beaucoup changé depuis vingt ans, le diagnostic, la classification par stade et la prise en charge du cancer du poumon se sont améliorés.

OBJECTIF : Décrire l'épidémiologie du cancer pulmonaire primaire dans une cohorte de l'Alberta, avec une analyse des facteurs contribuant à la survie après deux ans.

PATIENTS ET MÉTHODOLOGIE : Six cent onze Albertains ayant reçu un diagnostic de cancer pulmonaire primaire en 1998 ont été repérés grâce au registre du cancer de l'Alberta. Par une étude des dossiers médicaux, des données démographiques et cliniques ont été colligées pendant une période maximale de deux ans à compter de la date de diagnostic.

RÉSULTATS : L'âge moyen au diagnostic était de 66,5 ans. La majorité des cas (92\%) étaient des fumeurs. Les adénocarcinomes, suivis des carcinomes épidermoïdes, constituaient les histologies de cancers pulmonaires non à petites cellules les plus fréquentes. Les adénocarcinomes étaient plus fréquents chez les femmes, et les carcinomes épidermoïdes, chez les hommes. Après deux ans, les taux de survie globaux des cancers pulmonaires non à petites cellules, à petites cellules ou d'autres formes s'élevaient à $26 \%$, à $10 \%$ et à $13 \%$, respectivement. Dans l'analyse multivariée, la classification par stade, la chirurgie pulmonaire et la chimiothérapie s'associaient de manière significative à la survie des carcinomes non à petites cellules après deux ans. Seules la classification par stade et la chimiothérapie étaient importantes en cas de carcinomes à petites cellules. CONCLUSIONS : L'étude fournit un point de vue épidémiologique canadien, qui correspond en général à la documentation scientifique nord-américaine. Une surveillance continue de l'épidémiologie du cancer du poumon est essentielle pour évaluer les répercussions de la progression du diagnostic, de la classification par stade et de la prise en charge du cancer du poumon. Une analyse clinique et économique plus approfondie, fondée sur les données colligées dans cette cohorte, est prévue.
\end{abstract}

T ung cancer is the leading cause of cancer death and resultLed in an estimated 18,400 deaths in Canada in 2002. Lung cancer rates continue to rise in women and have begun to decline in men, correlating with historical smoking rates. Lung cancer incidence rates are second only to prostate cancer in men and breast cancer in women (1).

Lung cancer survival rates have not changed significantly over the past two decades (2,3). The 1992 Canadian and Alberta five-year survival rates were only $13 \%$ and $10 \%$, respectively (4). In fact, lung cancer has the second highest

${ }^{1}$ Radiology and Diagnostic Imaging, University of Alberta, Edmonton, Alberta (currently - joint appointments, Department of Radiology,

Section of Nuclear Medicine, and Department of Community Health Sciences, University of Manitoba, Winnipeg, Manitoba);

${ }^{2}$ Alberta Cancer Board, Cross Cancer Institute, Edmonton, Alberta; ${ }^{3}$ Public Health Sciences, University of Alberta, Edmonton, Alberta

Correspondence and reprints: Dr Sandor Demeter, Room GC345, Section of Nuclear Medicine, Health Sciences Centre, 820 Sherbrook Street,

Winnipeg, Manitoba R3A 1R9. Telephone 204-787-3375, fax 204-787-3090, e-mail sdemeter@shaw.ca 
case fatality rate of $88 \%$, with pancreatic cancer having the highest rate at $99 \%$ (1).

However, there has been progress in patient selection, which has significantly reduced operative mortality rates from $10 \%$ to $3 \%(5)$. There have also been significant changes in staging protocols, which have allowed increased selectivity in determining who benefits from surgery (6). Thus, one could argue that while there have been no significant changes in overall lung cancer case fatality rates, there has been progress in patient selection that improves quality of life by avoiding nonbeneficial, invasive procedures. There have also been promising advances in chemotherapy and radiotherapy (7), which have the greatest impact as adjuvant or palliative therapy.

More recently, good evidence has been found that 18-fluorodeoxyglucose positron emission tomography (FDG-PET) imaging contributes to further improvements in the accuracy of lung cancer staging (8-10), which further improves patient selection, especially with regard to surgical interventions. To date, there has been slow adoption of PET technology in Canada (11). This is in contrast to the more rapid adoption and diffusion of PET technology in the late 1990s in the United States and Europe. Increased use in the United States was primarily related to an increase in approved indications, including the investigation of solitary pulmonary nodules and the staging of lung cancer.

In addition, there is continued and increasing interest in computed tomography lung cancer screening programs. For example, Nawa et al (12) recently published promising results regarding the detection of early or stage I disease with low dose computed tomography screening in a large occupational cohort.

To study the impact of continued advances in the staging and management of lung cancer, it is appropriate to establish a baseline reference and review the epidemiology of a recent Canadian lung cancer cohort. This paper is a descriptive analysis of the epidemiology of primary lung cancer in an Alberta cohort with an analysis of factors contributing to survival to two years. These data will serve as a foundation for future analysis with regard to clinical outcomes and health utilization costs.

\section{PATIENTS AND METHODS}

A PubMed (National Library of Medicine) literature search was conducted of literature cited from 1966 to July 2002.

The study population was drawn from the Edmonton Cross Cancer Institute (CCI)'s (Edmonton, Alberta) catchment area. This consists of Regional Health Authorities 6 through 17 inclusive (as per 1998 Health Authority boundaries, total population=1,599,817). The study cohort was identified through the Alberta Cancer Registry (ACR) and included the 1998 incident cases of primary bonchogenic lung cancer as classified by the International Classification of Diseases Oncology. The numbers are provisional because some cases (or deaths) may be registered in subsequent years. Methods for the coding of cancers on the ACR have varied through the years. Therefore, caution should be exercised when comparing data with those of previous years.

The northern one-half of the province was chosen to maximize the likelihood of clinical charts being available at the CCI. A 1998 cohort was chosen because this was the most recent year for which complete data were available.
Chart reviews were conducted by an experienced health care worker. Data were transcribed onto paper data abstraction forms, which were developed through iterative consultation with individuals having specific content and methodological knowledge relative to this research. The first 15 abstracted charts were comprehensively reviewed by the first author as a validation exercise and no significant deviations were demonstrated. In addition, if there was uncertainty related to any data variable, the chart was set aside for review by the first author.

An electronic database emulating the data abstraction form was constructed using FileMaker Pro 5 software (Filemaker Inc, USA).

The diagnosis date was defined as the date of most definitive diagnosis as per the ACR Coding Manual (13). In broad categories, histopathology was the most definitive diagnosis, followed by cytology, diagnostic imaging and clinical impression. On average, patients were assessed at the CCI within 23 days of diagnosis ( $95 \%$ CI 15 to 30 days).

ACR records, which are regularly updated and linked to provincial vital statistics and national mortality databases, were used to assess survival to two years from the date of diagnosis. Staging for nonsmall cell lung carcinoma (NSCLC) was determined as per the 1997 Revisions in the International System for Staging Lung Cancer (14). If a separate surgical stage was recorded, then the surgical stage was used; otherwise, the clinical stage was used.

Small cell lung carcinoma (SCLC) stage was recorded as limited or extensive based on the impression recorded by the clinician at the patient's initial attendance at the CCI.

Urban versus rural residence was determined as per Canada Post definitions using postal codes (15).

For the survival analysis, radiotherapy and chemotherapy were defined as the patient having had at least one external beam radiotherapy or chemotherapy treatment or session relating to lung cancer. Thoracic surgery included open lung biopsy, wedge resection, segmental resection, lobectomy and pneumonectomy. Mediastinoscopy included all utilized techniques in this cohort (ie, routine, anterior and extended).

A direct method was used for the calculation of age-standardized primary lung cancer incidence rates using the 1991 Canadian standard population, as published in the National Cancer Institute of Canada, Canadian Cancer Statistics, 1998 monograph (16).

Statistical analysis was completed using SPSS Base 10.0 software (SPSS Inc, USA). Where appropriate, $\chi^{2}$ and Student's $t$ tests were used.

For the survival analysis, a Cox's proportional regression survival analysis was used. The hazard ratios and their CIs are given. The hazard ratio, for a suspect prognostic variable, is mathematically determined from the derived survival curve and is a measure of the relative risk of not surviving relative to the baseline or reference state of the chosen variable. For example, in a dichotomous variable, such as presence or absence of a hypothesized prognostic variable, a hazard ratio of 2 would infer a two times relative risk of dying, with the variable being positive versus absent. The proportional hazards assumption was tested by generating and inspecting the log-minus-log plots. Exact age at diagno- 
TABLE 1

Frequency of histological diagnoses

\begin{tabular}{lc}
\hline Histology & Number (\%) \\
\hline Adenocarcinoma & $250(41)$ \\
Squamous cell carcinoma & $143(23)$ \\
Large cell carcinoma & $53(9)$ \\
Bronchoalveolar & $6(1)$ \\
Mucoepidermoid & $1(<1)$ \\
Carcinoid & $7(1)$ \\
Small cell & $105(17)$ \\
Unspecified carcinoma & $39(6)$ \\
Unspecified cancer & $7(1)$ \\
NSCLC total & \\
SCLC total & $452(74)$ \\
Other total & \\
Total $^{*}$ & $105(17)$
\end{tabular}

*NSCLC (nonsmall cell lung carcinoma) includes adenocarcinoma, squamous cell, large cell and bronchoalveolar carcinomas; Other includes mucoepidermoid, carcinoid, unspecified carcinomas and unspecified cancer. SCLC Small cell lung carcinoma

sis was entered as a continuous variable, decade of diagnosis as an ordinal variable and all other variables as categorical variables. A forced entry model was used for the multivariate analysis.

Statistically significant results were declared at $\mathrm{P}<0.05$ (two-tailed). CIs are reported (95\%) when appropriate.

This research protocol was granted ethics approval from the Alberta Cancer Board Research Ethics Committee.

\section{RESULTS}

Of the 742 individuals initially identified through the ACR, three cases were excluded because they did not have primary lung cancer diagnoses (ie, two lymphomas and one lung cancer recurrence). Of the remaining 739 individuals, 128 were listed on the cancer registry but had insufficient information for comprehensive clinical review (ie, no charts, no microfiches or no significant clinical entries). Only demographic and tumour histology information could be collected for these 128 individuals. Detailed demographic, clinical and health utilization data were collected from the remaining 611 individuals ( $83 \%$ of the identified 739 cases from the 1998 incident primary lung cancer cases).

The male, female and sex-combined, age-standardized primary lung cancer incidence rates per 100,000 people were 62 , 42 and 50, respectively $(n=739)$.

Unless otherwise specified, all further analyses are based on the 611 primary lung cancer cases for which more detailed clinical information was available.

The mean $( \pm$ SD) age at time of diagnosis was $66.5 \pm 11$ years (range 14 to 93 years). On average, men were slightly older than women (67.6 versus 65.1 years, $\mathrm{P}=0.005$ ). Men accounted for $55 \%$ of the cohort. The majority of cases $(79 \%)$ had urban residences, with the remainder having rural residences. The urban-rural split concurs with that of the general Alberta population as per 1996 Canadian Census data (17).

Table 1 illustrates the frequency of histological diagnosis. Overall, adenocarcinoma and squamous cell carcinoma were the most frequent NSCLC histologies. There were no significant
TABLE 2

Frequency of stage at presentation and per cent survival to two years from date of diagnosis

\begin{tabular}{lcc}
\hline Cancer type and stage & $\mathbf{n}(\%)$ & Survival rate (\%) \\
\hline Nonsmall cell carcinoma* & & \\
I & $68(15)$ & 83 \\
II & $27(6)$ & 63 \\
IIla & $46(10)$ & 28 \\
IIIb & $105(23)$ & 14 \\
IV & $165(37)$ & 3 \\
[I-IV] & {$[411(91)]$} & {$[26]$} \\
Unspecified stage & $41(9)$ & 17 \\
All & $452(100)$ & 24 \\
Small cell carcinoma & & \\
Limited & $35(33)$ & 22 \\
Extensive & $67(64)$ & 4 \\
[Limited and extensive] & {$[102(97)]$} & {$[11]$} \\
Unspecified stage & $3(3)$ & 0 \\
All & $105(100)$ & 10 \\
Other* & & 13 \\
I-IV & $40(76)$ & 15 \\
Unspecified stage & $14(24)$ & 13 \\
All & $54(100)$ & $\mathbf{2 2}$ \\
Overall & $\mathbf{6 1 1 ( 1 0 0 )}$ &
\end{tabular}

*Nonsmall cell lung carcinoma includes adenocarcinoma, squamous cell, large cell and bronchoalveolar carcinomas; Other includes mucoepidermoid, carcinoid, unspecified carcinomas and unspecified cancer

differences in the distribution of the broad categories of NSCLC, SCLC and 'other' lung cancers by sex.

Among patients with NSCLC, the proportion of adenocarcinoma was significantly higher in women $(60 \%$ women and $51 \%$ men, $\chi^{2}$ test $\left.\mathrm{P}=0.04\right)$, with the proportion of squamous cell carcinoma higher in males (38\% men and 24\% women, $\chi^{2}$ test $\left.\mathrm{P}=0.003\right)$. Other NSCLC histologies demonstrated no significant differences in distribution by sex.

There was no significant difference in the distribution of histologies by urban versus rural residence or by stage of disease.

Smoking 'yes/no' data was collected in $93 \%$ of the cohort. The vast majority (92\%) were declared smokers. Among smokers, there was a mean $( \pm$ SD) of $40 \pm 12$ years of smoking per individual (data available for $67 \%$ of declared smokers) and a mean $( \pm$ SD) of $44 \pm 15$ pack-years of smoking (data available for $39 \%$ of declared smokers). There was a significantly higher proportion of smokers in the squamous (132 of $136,97 \%$ ) and small cell (96 of 98, 98\%) carcinoma groups than in the adenocarcinoma (204 of 234, 87\%) group, with $\mathrm{P}=0.002$ and $\mathrm{P}=0.002$, respectively.

The frequency of presenting stage and survival to two years is illustrated in Table 2. Staging information was available for 91\% of patients (411 of 452) with NSCLC, 97\% of patients (102 of 105) with SCLC and 76\% of patients (41 of 54) with 'other' lung cancers. The 'other' lung cancers category was collapsed due to small numbers. In 38 cases, both clinical and surgical stages were recorded, with disagreements in only three instances (surgical stage lower than clinical stage in two cases and higher than clinical stage in one case). Information on survival to two years from the date of diagnosis was available for 
TABLE 3

Interventions stratified by type of lung cancer and presenting stage

\begin{tabular}{lcccc}
\hline $\begin{array}{l}\text { Cancer type } \\
\text { and presenting } \\
\text { stage (n) }\end{array}$ & $\begin{array}{c}\text { Mediastino- } \\
\text { scopy (\%) }\end{array}$ & $\begin{array}{c}\text { Invasive } \\
\text { thoracic } \\
\text { surgery* }\end{array}$ (\%) & $\begin{array}{c}\text { Chemotherapy } \\
(\%)\end{array}$ & $\begin{array}{c}\text { External beam } \\
\text { radiotherapy } \\
(\%)\end{array}$ \\
\hline Nonsmall cell lung carcinoma & & & \\
I (68) & 18 & 85 & 9 & 26 \\
II (27) & 30 & 85 & 7 & 41 \\
IIla (46) & 28 & 46 & 15 & 89 \\
IIIb (105) & 24 & 12 & 12 & 81 \\
IV (165) & 10 & 5 & 18 & 82 \\
All (411) & 18 & 30 & 14 & 71 \\
Small cell lung carcinoma & 31 & 3 & 86 & 83 \\
Limited (35) & 8 & 1 & 64 & 63 \\
Extensive (67) & 16 & 2 & 72 & 70 \\
All (102) & & & & \\
\hline
\end{tabular}

*Includes open lung biopsy, wedge resection, segmentectomy, lobectomy and pneumonectomy; tIncludes adenocarcinoma, squamous cell, large cell and bronchoalveolar carcinomas; $¥$ Surgeries included one open lung biopsy and one pneumonectomy

TABLE 4

Number of surgical interventions by stage for nonsmall cell lung carcinoma

\begin{tabular}{lrrrrr}
\hline & \multicolumn{5}{c}{ Stage } \\
\cline { 2 - 6 } Type of surgery & I & II & IIIA & IIIB & IV \\
\hline Open lung biopsy & 0 & 0 & 2 & 6 & 3 \\
Wedge resection & 4 & 0 & 0 & 1 & 0 \\
Segmental resection & 1 & 0 & 2 & 0 & 0 \\
Lobectomy & 49 & 13 & 9 & 3 & 1 \\
Pneumonectomy & 4 & 10 & 8 & 0 & 4 \\
Unspecified & 0 & 0 & 0 & 3 & 0 \\
No surgery & 10 & 4 & 25 & 92 & 157 \\
Total (\% with & $68(85)$ & $27(85)$ & $46(46)$ & $105(12)$ & $165(5)$ \\
$\quad$ surgical intervention) & & & & & \\
\hline
\end{tabular}

all 611 individuals. Although there was a reasonable survival rate to two years for patients with NSCLC stage I and II, that is, $83 \%$ and $63 \%$, respectively, only a minority of individuals (ie, 21\%) presented in these early stages. There was a rapid decline in the survival rate to two years by increasing stage for NSCLC and poor survival in SCLC irrespective of stage. The overall survival rate for 'other' lung cancers was worse than the overall survival rate for NSCLC.

Table 3 describes the frequency of various interventions by cancer type and presenting stage. Only cases with known stages were included, and 'other' cancers were not included due to small numbers. For NSCLC, general trends that were observed were expected increased surgical rates at lower stages, and increased chemotherapy and radiotherapy interventions at higher stages. Mediastinoscopy rates were lower than expected, and this may be related to failure to capture these events. As expected, chemotherapy and radiotherapy rates were high for both limited and extensive SCLC.

Table 4 provides details of the types of surgical interventions for patients with NSCLC by stage. Proportionately more

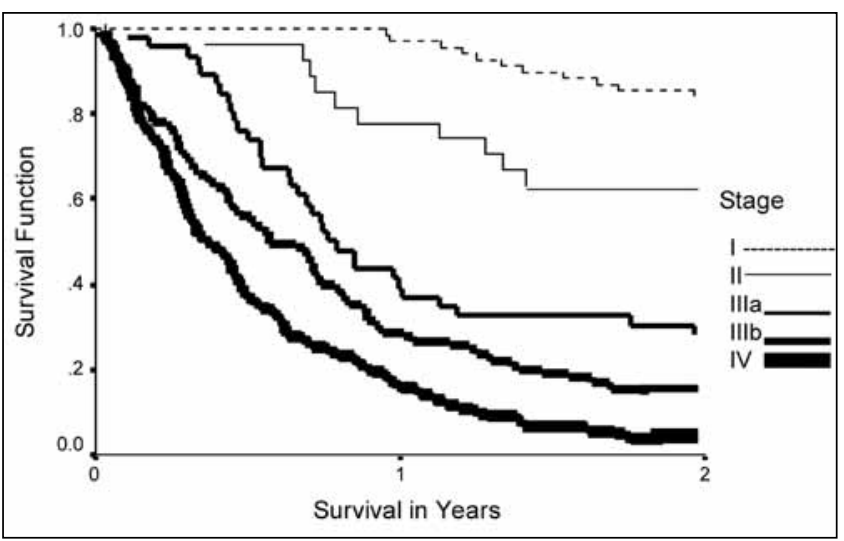

Figure 1) Survival to two years by stage in patients with nonsmall cell lung carcinoma

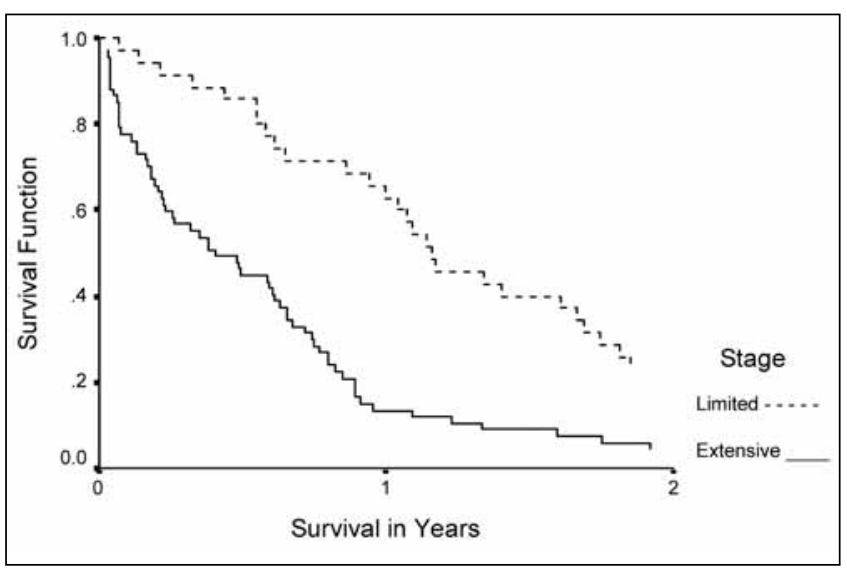

Figure 2) Survival to two years by stage in patients with small cell carcinoma

aggressive surgery was observed in lower stages. For example, the proportion of any form of resection (wedge, segment, lobe or lung) was $71 \%$ for stages I through IIIa combined and 3\% for stages IIIb and IV combined.

Unadjusted survival curves for NSCLC and SCLC, stratified by stage, are illustrated in Figures 1 and 2, respectively.

A univariate Cox regression analysis of survival to two years stratified by NSCLC and SCLC, as well as by stage, was conducted on the following variables: patient age at date of diagnosis (exact age and decade), urban or rural residence, sex, smoker ('yes or no'), number of years smoking, number of pack-years smoked, histology (for NSCLC and other cancers), stage, mediastinoscopy, surgery, chemotherapy and radiotherapy. The latter four variables were entered as binary 'yes or no' variables. Events were censored at two years from the date of diagnosis. Due to small numbers, 'other' cancers were not included. Table 5 illustrates the results of the univariate analysis.

Stratified by NSCLC and SCLC, variables that achieved univariate significance were included in multivariate Cox's proportional hazards regression models. Interaction was assessed in NSCLC for mediastinoscopy surgery, mediastinoscopy stage, surgery stage and chemotherapy stage. Interaction was assessed in SCLC for radiotherapy stage and chemotherapy stage. No significant interactions were found 
TABLE 5

Cox regression analysis* of selected variables

\begin{tabular}{|c|c|c|c|}
\hline Variable & $\begin{array}{l}\text { Type of } \\
\text { cancer }^{\dagger}\end{array}$ & $\begin{array}{c}\text { Hazard } \\
\text { ratio }^{\dagger}\end{array}$ & $\begin{array}{l}95 \% \mathrm{Cl} \text { for } \\
\text { hazard ratio }\end{array}$ \\
\hline \multirow[t]{2}{*}{ Age (years) at date of diagnosis } & NSCLC & NS & \\
\hline & SCLC & 1.04 & 1.02 to 1.06 \\
\hline \multirow[t]{2}{*}{ Sex (female reference) } & NSCLC & 1.3 & 1.1 to 1.6 \\
\hline & SCLC & NS & \\
\hline \multirow[t]{2}{*}{ Number of pack-years smoked } & NSCLC & NS & \\
\hline & SCLC & 1.02 & 1.003 to 1.04 \\
\hline \multicolumn{4}{|l|}{ Stage f $^{\ddagger}$} \\
\hline 1 & NSCLC & Reference & \\
\hline II & & 2.7 & 1.1 to 6.3 \\
\hline IIla & & 7.6 & 3.9 to 15.1 \\
\hline $\mathrm{Ill \textrm {lb }}$ & & 12.3 & 6.6 to 23.2 \\
\hline IV & & 19.9 & 10.7 to 37.0 \\
\hline Limited & SCLC & Reference & \\
\hline Extensive & & 2.8 & 1.8 to 4.4 \\
\hline Mediastinoscopy§ & NSCLC & 0.7 & 0.5 to 0.9 \\
\hline Surgery§ & NSCLC & 0.2 & 0.1 to 0.3 \\
\hline \multirow[t]{2}{*}{ Radiotherapy§ } & NSCLC & 2.0 & 1.6 to 2.6 \\
\hline & $\mathrm{SCLC}$ & 0.4 & 0.2 to 0.5 \\
\hline \multirow[t]{2}{*}{ Chemotherapy§ } & NSCLC & 0.7 & 0.5 to 0.9 \\
\hline & $\mathrm{SCLC}$ & 0.2 & 0.1 to 0.3 \\
\hline
\end{tabular}

*Univariate analysis - survival to two years from the date of diagnosis; tHazard Ratio equals $\operatorname{Exp}(B)$ in SPSS output and is related to the risk, relative to the baseline or reference condition, of not surviving to two years from the date of diagnosis: ₹Stage entered as a categorical variable with stage I or limited stage as the reference comparator; \$Mediastinoscopy included all used techniques in this cohort (ie, routine, anterior and extended); Surgery included open lung biopsy, wedge resection, segmental resection, lobectomy or pneumonectomy; Radiotherapy and chemotherapy treatments or sessions were related to the patient's lung cancer. NS Not significant; NSCLC Nonsmall cell lung carcinoma; SCLC small cell lung carcinoma

when all interaction variables and the univariate significant variables were entered into the model. For NSCLC, stage, surgery and chemotherapy remained significant. For SCLC only, stage and chemotherapy remained significant. Table 6 provides the detailed results of the multivariate analysis.

\section{DISCUSSION}

Our data demonstrate that for NSCLC, adenocarcinoma was the most frequent histology at $55 \%$, followed by squamous cell carcinoma (32\%), large cell carcinoma (12\%) and bronchoalveolar cell carcinoma (2\%). This correlates to the North American literature $(2,18,19)$, which also show a preponderance of adenocarcinoma over squamous cell carcinoma. It should be noted that the European literature demonstrates the opposite, that is, a preponderance of squamous cell carcinoma over adenocarcinoma (18).

Previously published Canadian data (20), based on a 1984 Alberta cohort, reported 26\%, 15\%, 22\% and 37\% proportions for stages I, II, III and IV, respectively. Our data demonstrated $16 \%, 6 \%, 37 \%$ and $41 \%$ per stage, respectively. There is an apparent increase in the proportion of later stages in our data. One reason for this difference may be due to different proportions of unstaged cases. In our NSCLC data, only $9 \%$ of cases (41 of 452) were of an unspecified stage, whereas Gentleman et al (20) reported that $41 \%$ (283 of 683 ) were
TABLE 6 Multivariate Cox regression analysis* of selected variables

\begin{tabular}{|c|c|c|c|}
\hline Variable & $\begin{array}{l}\text { Type of } \\
\text { cancer }\end{array}$ & $\begin{array}{c}\text { Hazard } \\
\text { ratio }^{\dagger}\end{array}$ & $\begin{array}{c}95 \% \mathrm{Cl} \text { for } \\
\text { hazard ratio }\end{array}$ \\
\hline \multicolumn{4}{|l|}{ Stage $e^{\ddagger}$} \\
\hline 1 & NSCLC & Reference & \\
\hline II & & 2.7 & 1.2 to 6.4 \\
\hline Illa & & 6.4 & 3.1 to 13.2 \\
\hline Illb & & 9.0 & 4.6 to 17.9 \\
\hline IV & & 14.5 & 7.3 to 29.0 \\
\hline Limited & SCLC & Reference & \\
\hline Extensive & & 2.2 & 1.02 to 4.9 \\
\hline Surgery§ & NSCLC & 0.5 & 1.02 to 4.9 \\
\hline \multirow[t]{2}{*}{ Chemotherapy§ } & NSCLC & 0.5 & 0.4 to 0.7 \\
\hline & SCLC & 0.02 & 0.002 to 0.1 \\
\hline
\end{tabular}

*Forced entry model, survival to two years from the date of diagnosis; tHazard Ratio equals $\operatorname{Exp}(B)$ in SPSS output and is related to the risk, relative to the baseline or reference condition, of not surviving to two years from the date of diagnosis, ¥Stage entered as a categorical variable with stage I or limited stage as the reference comparator; \$Mediastinoscopy included all used techniques in this cohort (ie, routine, anterior and extended); Surgery included open lung biopsy, wedge resection, segmental resection, lobectomy or pneumonectomy; Radiotherapy and chemotherapy treatments or sessions were related to the patient's lung cancer. NSCLC Nonsmall cell lung carcinoma; SCLC Small cell lung carcinoma

unstaged. Furthermore, we did not assign imputed stages to our unstaged data, whereas Gentleman et al did. Gentleman et al state that their imputation methodology resulted in a reduction of stage IV disease and a corresponding increase in earlier stages. Other reasons for the apparent difference in distribution of stages may be differences in data collection methodology or changes in methods for assigning stage. It would seem unlikely that the differences are due to a trend of diagnosis at a later stage in time (ie, 1984 versus 1998). It is also unlikely that our methodology was biased toward staging people at a later course in their disease, because stage was assigned based on investigations surrounding the date of diagnosis.

Gentleman et al (20) also reported that only $27 \%$ of their 1984 cohort were female (SCLC and NSCLC), which is significantly different than our study, in which $45 \%$ were female. This difference is thought to be due to the fact that lung cancer incidence rates have been rising faster in women than men for the past few decades, most likely due to different sex-specific smoking rates. Our data, with respect to proportions of lung cancer cases by sex, generally agree with the 1998 Canadian Cancer Statistics figures for Alberta (ie, $42 \%$ female) (16).

In another Canadian, retrospective, cohort-based study of 169 patients diagnosed with NSCLC between 1988 and 1990, Ouellette et al (21) reported proportions by stages (female/male) of $25 \% / 26 \%, 2 \% / 6 \%, 20 \% / 34 \%, 6 \% / 7 \%$ and $25 \% / 19 \%$ for stages I, II, IIIa, IIIb and IV, respectively. Their data have proportionately more lower stage cases than ours. The differences may be due to different study populations. Our data were based on a Cancer Registry population, while the data reported by Ouellette et al were based on a retrospective cohort (consecutive cases) of individuals attending to a university hospital. 
TABLE 7

\section{Survival rates to two years by stage - A comparison with the literature}

\begin{tabular}{lccc}
\hline $\begin{array}{l}\text { Stage - } \\
\text { NSCLC }\end{array}$ & $\begin{array}{c}\text { Present study } \\
\text { survival ratios } \\
(\mathbf{n = 4 1 1 )}(\%)\end{array}$ & $\begin{array}{c}\text { Mountain* } \\
\text { clinical staging } \\
(\mathbf{n}=\mathbf{5 2 3 0})(\%)\end{array}$ & $\begin{array}{c}\text { Mountain* } \\
\text { surgical staging } \\
(\mathbf{n = 1 9 1 0 )}(\%)\end{array}$ \\
\hline la & $30 / 31(97)$ & 79 & 86 \\
$\mathrm{Ib}$ & $25 / 33(76)$ & 54 & 76 \\
$\mathrm{I}^{\dagger}$ & $56 / 68(83)$ & 66 & 81 \\
$\mathrm{Ila}$ & $7 / 10(70)$ & 49 & 70 \\
$\mathrm{Ilb}$ & $10 / 16(63)$ & 41 & 56 \\
$\mathrm{II}$ & $17 / 27(66)$ & 44 & 61 \\
IIIa & $13 / 46(28)$ & 25 & 40 \\
IIIb & $15 / 105(14)$ & 13 & \\
IV & $5 / 165(3)$ & 6 & \\
Stages I to IV & $107 / 411(26)$ & 22 & \\
\hline
\end{tabular}

*Data from reference $14 ;{ }^{\dagger}$ Four stage I cancers and one stage II cancer were not subcategorized. NSCLC Nonsmall cell lung carcinoma

Compared with a large, clinically staged, North American lung cancer cohort $(\mathrm{n}=5230)$ (14), our population experienced longer two-year survival rates for stages I through III, with minimal differences for stages IIIb and IV. However, our survival results are closer to the surgically staged cohort $(n=1910)$ published in the same paper (14). One possible reason for these differences is that Mountain's (14) clinically staged cohort included small cell carcinoma ( $\mathrm{n}=642$ or $11.9 \%$ of the cohort), and their surgically staged cohort did not. Our data show that small cell carcinoma has a generally poorer prognosis than large cell carcinoma, and we have analyzed it separately. This may account for the difference between our data and Mountain's clinically staged cohort, as well as the agreement with their surgically staged cohort. Table 7 summarizes these comparisons.

Fry et al (22) also reported survival by stage in a large $(\mathrm{n}=713,043)$ American lung cancer cohort (NSCLC and SCLC combined) diagnosed between 1985 and 1995. The two-year survival rates by stage were $59 \%, 41 \%, 24 \%, 13 \%$ and $5 \%$ for stages I, II, IIIa, IIIb and IV, respectively, which is similar to Mountain et al's (14) clinically staged cohort.

The relatively high two-year survival rate for patients with stage I NSCLC in our cohort (85\%) is in agreement with a recent review by Dominioni et al (23). This supports the benefit of early diagnosis, and Dominioni et al go further to argue that relatively high two-year survival rates support targeted screening of high-risk individuals (eg, smokers).

\section{REFERENCES}

1. Canadian Cancer Statistics 2002. Toronto: National Cancer Institute of Canada, 2002.

2. Smith RA, Glynn TJ. Epidemiology of lung cancer.

Radiol Clin North Am 2000;38:453-70.

3. Williams MD, Sandler AB. The epidemiology of lung cancer. Cancer Treat Res 2001;105:32-52.

4. Ellison LF, Gibons L, Canadian Cancer Survival Analysis Group. Five-year relative survival from prostate, breast, colorectal and lung cancer. Health Rep 2001;13:23-34. (Statistics Canada 82-003)

5. Pearson FG. Lung cancer. The past twenty-five years. Chest 1986;89(Suppl 4):200S-5S.

6. Bunn PA, Kelly K. New combinations in the treatment of lung cancer: A time for optimism. Chest 2000;117(Suppl 1):S138-43.

7. Choy H, MacRae R. The current state of paclitaxel and radiation in the combined-modality therapy of non-small cell lung cancer. Semin Oncol 2001;28(Suppl 14):17-22.
There were 128 individuals identified on the ACR who had insufficient information for full analysis. The majority of these cases never attended the CCI or had very little information available in CCI charts. They either went to an alternate Alberta Cancer Centre or never presented to any Alberta Cancer Centre. It is possible that some only sought community-based palliative care and that some only received curative surgery.

However, basic demographic and survival data were available for these 128 individuals. When compared with our study cohort $(\mathrm{n}=611)$, the mean age of this group was older, at 72.2 years $(\mathrm{P}<0.0001), 59 \%$ were male (not significant $[\mathrm{NS}]$ ), $88 \%$ were urban (NS) and $22 \%$ survived to two years from the date of diagnosis (NS). It is reassuring to note that this cohort experienced a similar overall survival rate and were similar with regard to sex and urban or rural composition.

Lung cancer is a preventable disease. The fact that the vast majority of our cohort (92\%) smoked at some point in their life, with an average of 40 years and 44 pack-years of smoking, does not come as a surprise. It has been well established that smoking accounts for $80 \%$ to $90 \%$ of the population attributable risk for primary lung cancer (24), and that the incidence of primary lung cancer closely correlates to smoking rates, with a latent period of 15 to 20 years (25). We would be remiss if we failed to state that the single most effective intervention in the fight against lung cancer is to reduce the population's primary or secondary exposure to inhaled tobacco smoke.

\section{CONCLUSIONS}

The present study describes the epidemiology and survival experience of a relatively large 1998 Canadian cohort with primary lung cancer. This research provides a Canadian baseline for which to assess established, newly adopted and future technologies or interventions relative to primary lung cancer. Based on data collected to date on this cohort, further clinical and economic analysis, including a cost-effectiveness analysis of FDG-PET imaging for the staging and management of primary lung cancer, is planned.

ACKNOWLEDGEMENTS: Partial financial support was provided by an unrestricted award from Amersham Health (Radiant Award) and by the Canada Foundation for Innovation. The Cross Cancer Institute and the University of Alberta Radiology and Diagnostic Imaging Department - Nuclear Medicine Residency Training Program are acknowledged for their support.

8. Gambhir SS, Czernin J, Schwimmer J, Silverman HS, Coleman RE, Phelps ME. A tabulated summary of the FDG PET literature. J Nucl Med 2001;42(Suppl 5):1S-8S.

9. Pieterman RM, van Putten JWG, Meuzelaar JJ, et al. Preoperative staging of non-small cell lung cancer with positron-emission tomography. N Engl J Med 2000;343:254-61.

10. Hicks RJ, MacManus KM, Ware RE, et al. 18F-FDG PET provides high-impact and powerful prognostic stratification in staging newly diagnosed non-small cell lung cancer. J Nucl Med 2001;42:1596-604.

11. Canadian Coordinating Office of Health Technology Assessment. National Inventory of Selected Imaging Equipment -

Positron Emission Tomography Scanners in Canadian Hospitals. $<$ www.ccohta.ca> (Version current at November 17, 2003).

12. Nawa, T, Nakagawa T, Kusano S, Kawasaki Y, Sugawara Y, Nakata H. Lung cancer screening using low-dose spiral CT: Results of baseline and 1-year follow-up studies. Chest 2002;122:15-20. 
13. Alberta Cancer Registry Coding Manual. Edmonton: Alberta Cancer Registry - Alberta Cancer Board, 1998.

14. Mountain CF. Revisions in the International System for Staging Lung Cancer. Chest 1997;111:1710-7.

15. Canada Postal Guide, October 2001. Ottawa: Canada Post, 2001.

16. National Cancer Institute of Canada. Canadian Cancer Statistics, 1998 monograph. Toronto: National Cancer Institute of Canada, 1998.

17. Statistics Canada Category Number 92-351-XPE. Ottawa: Industry Canada, 1997.

18. Charloux A, Rossignol M, Purohit A, et al. International differences in epidemiology of lung adenocarcinoma. Lung Cancer 1997;16:133-43.

19. Charloux A, Quoix E, Wolkove N, Small D, Pauli G, Kreisman H. The increasing incidence of lung adenocarcinoma: Reality or artifact? A review of the epidemiology of lung adenocarcinoma. Int J Epidemiol 1997;26:14-23.
20. Gentleman JF, Will BP, Berkel H, Gaudette L, Berthelot JM. The development of staging data for use in the microsimulation of lung cancer. Health Rep 1992;4:251-68. (Statistics Canada 82-003, Table 6)

21. Ouellette D, Desbiens G, Emond C, Beauchamp G. Lung cancer in women compared with men: Stage, treatment, and survival. Ann Thorac Surg 1998;66:1140-4.

22. Fry WA, Phillips JL, Menck HR. Ten-year survey of lung cancer treatment and survival in hospitals in the United States. Cancer 1999;86:1867-76.

23. Dominioni L, Imperatori A, Rovera F, Ochetti A, Torrigiotti G, Paolucci M. Stage I nonsmall cell lung carcinoma: Analysis of survival and implications for screening. Cancer 2000;89(Suppl 11):2334-44.

24. Osann KE. Epidemiology of lung cancer. Curr Opin Pulm Med 1998;4:198-204.

25. National Cancer Institute of Canada. Canadian Cancer Statistics, 2000. Toronto: National Cancer Institute of Canada, 2000:59. 


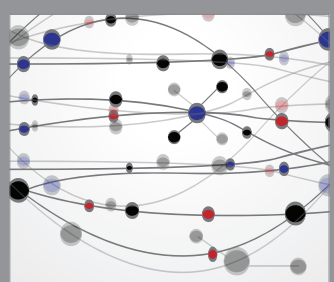

The Scientific World Journal
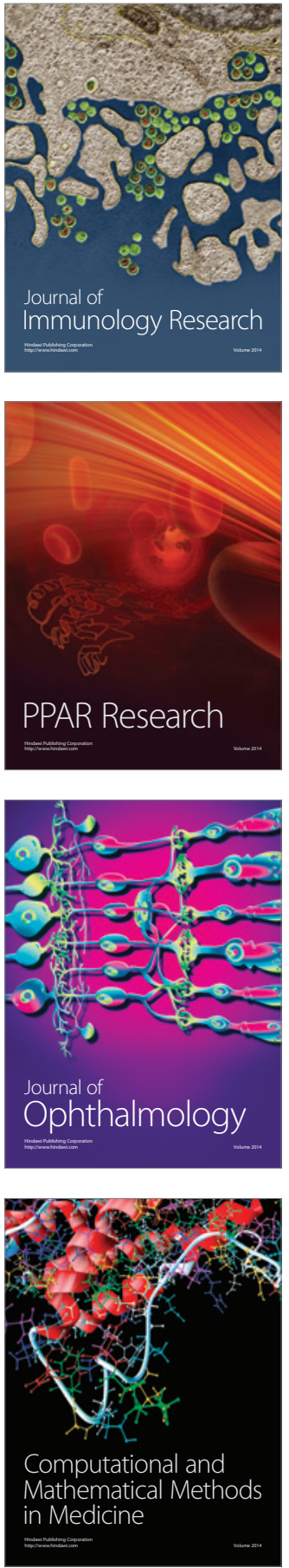

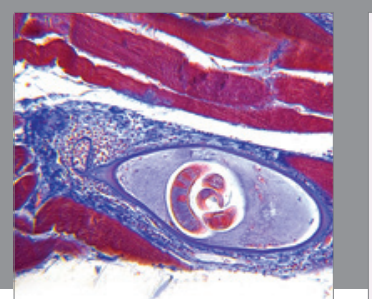

Gastroenterology Research and Practice

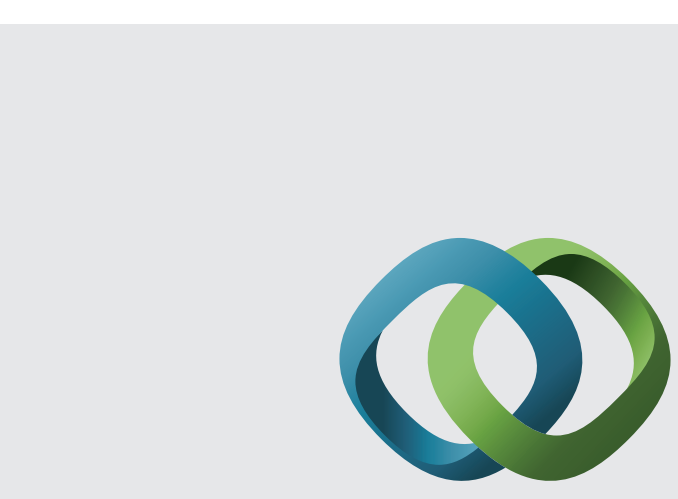

\section{Hindawi}

Submit your manuscripts at

http://www.hindawi.com
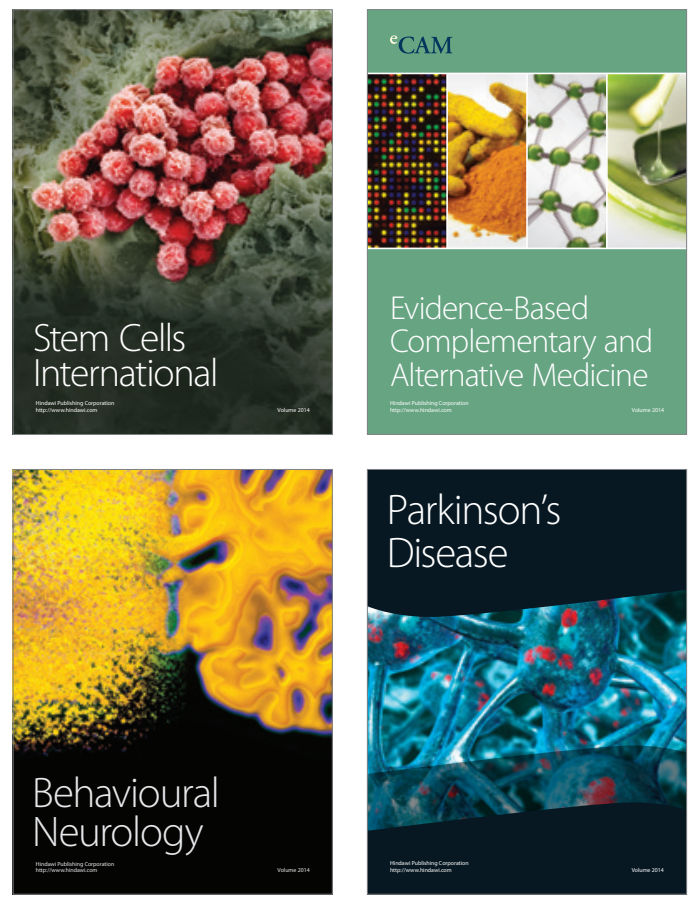
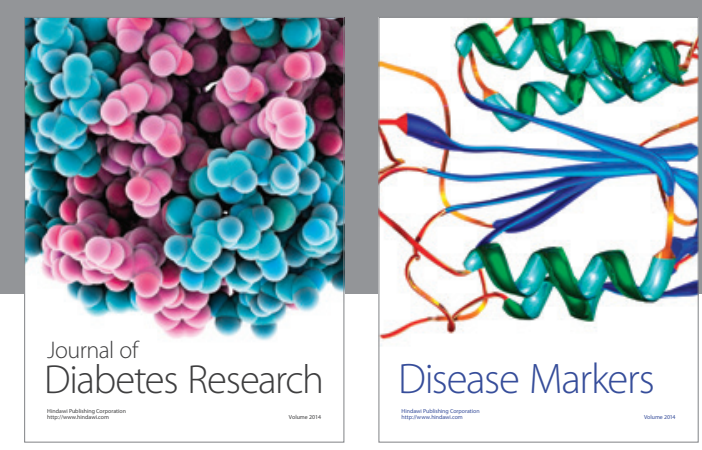

Disease Markers
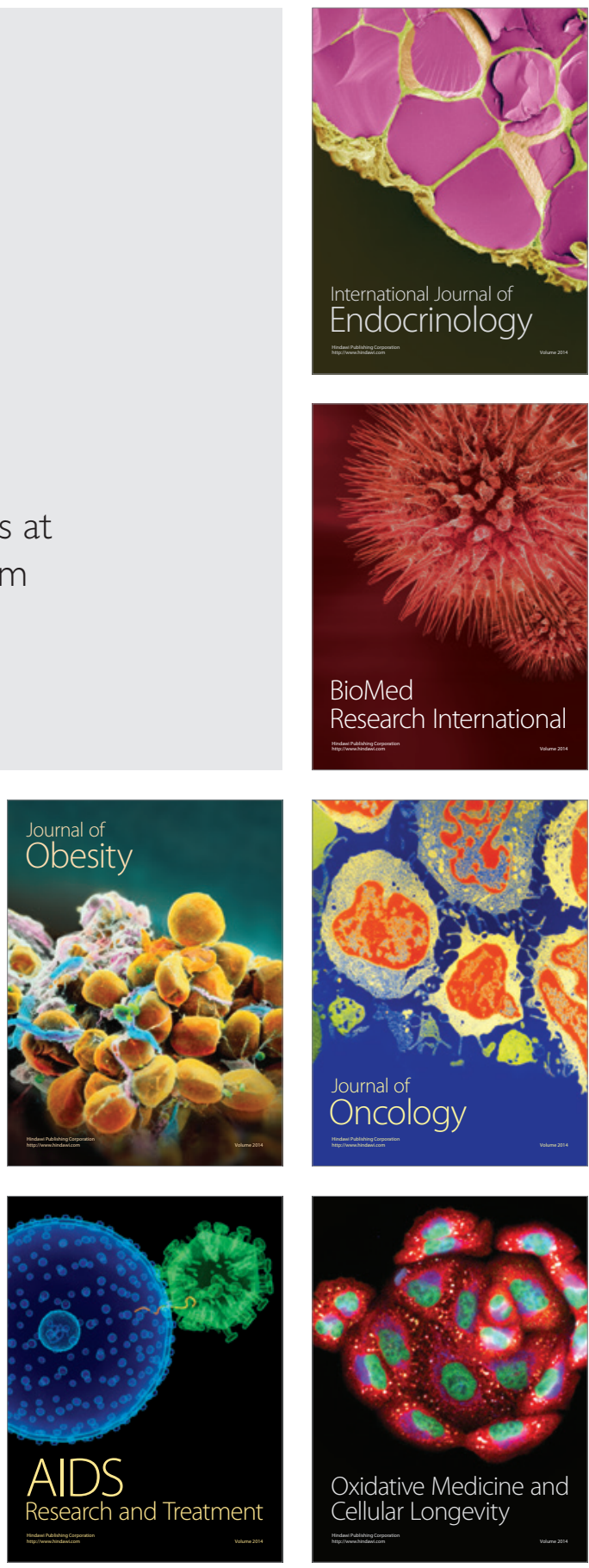